\title{
Exame Nacional de Desempenho de Estudantes: \\ mapeamento e tendências temáticas da produção \\ científica brasileira (2004 -2010)
}

\section{National Student Examination Performance: mapping and thematic tendencies of the Brazilian scientific production (2004-2010)}

\section{Adauto Marin Molck ${ }^{1}$}

admolck@hotmail.com

Adolfo Ignacio Calderón ${ }^{2}$

professoradolfocalderon@gmail.com

\section{Resumo}

Este artigo se insere no campo das pesquisas sobre as avaliações em larga escala, focalizando o Exame Nacional de Desempenho dos Estudantes (Enade). Partindo do consenso no âmbito governamental a respeito da necessidade do aprimoramento dos programas de avaliação para o aperfeiçoamento das políticas educacionais, apresenta-se o mapeamento e as tendências temáticas da produção científica brasileira em torno do Enade, tendo como referência dissertações de mestrado e teses de doutorado produzidas de 2004 a 2010.

Palavras-chave: Educação Superior, Enade, Avaliação da Educação, Estado da Arte, Sinaes

\begin{abstract}
This article is set into the field of educational research, specifically in studies of large-scale evaluation, focusing on the National Student Performance Exam (Enade ). In terms of methodology, it fits in studies on the state of the art, which aim to understand trends in scientific production about a certain theme. Based on the consensus within government about the need for improvement of programs assessment for the improvement of educational policies, this article presents the mapping and thematic trends Brazilian scientific production around the Enade , taking as reference the master dissertations and doctoral theses produced in Brazil since its inception in 2004 until 2010.
\end{abstract}

Keywords: Higher Education, Enade, Education Evaluation, State of Art, Sinaes.

\footnotetext{
${ }^{1}$ Comunicador Social, mestre em educação e docente da Faculdade de Jornalismo da Pontifícia Universidade Católica de Campinas.

${ }^{2}$ Doutor em ciências sociais pela Pontifícia Universidade Católica de São Paulo (Brasil), com PósDoutorado em ciências da educação pela Universidade de Coimbra (Portugal). Docentepesquisador no Programa de Mestrado em Educação da Pontifícia Universidade Católica de Campinas.
} 


\section{Introdução}

O Exame Nacional de Desempenho de Estudantes (Enade) foi instituído em abril de 2004, por meio da Lei 10.861 (BRASIL, 2004), quando foi aprovado o Sinaes - Sistema Nacional de Avaliação da Educação Superior, do qual é parte integrante, juntamente com a Avaliação das Instituições de Ensino Superior (AVALIES) e a Avaliação dos Cursos de Graduação (ACG).

Sustentado numa visão emancipatória e formativa da avaliação da educação superior, conforme Fiamini e Calderón (2012), o Enade é o equivalente ao Exame Nacional de Cursos (ENC), criado na gestão do presidente Fernando Henrique Cardoso (FHC), na medida em que ambos se constituem em instrumentos de avaliação do desempenho dos alunos em larga escala. Entretanto, diferentemente do ENC, que ranqueava avaliando somente o desempenho dos alunos concluintes, o Enade não permitia o ranqueamento, tendo como objetivo identificar habilidades e competências de universitários, em cada curso, ao longo de um ciclo de três anos de estudos, bem como o valor agregado dos cursos na formação dos alunos. Em termos operacionais, pode-se afirmar que o Enade direcionava-se, do ponto de vista epistemológico, para neutralizar o ranqueamento e a concorrência entre Instituições de Educação Superior (IES), práticas geradas pelo extinto ENC (CALDERÓN; POLTRONIERI; BORGES, 2011).

De acordo com a legislação (BRASIL, 2007), cabe ao Enade aferir o desempenho dos estudantes em relação aos conteúdos programáticos previstos nas diretrizes curriculares dos respectivos cursos de graduação, que deverão garantir, por sua vez, o desenvolvimento das habilidades e competências adquiridas em sua formação. O Enade originalmente foi desenhado para ser aplicado anualmente, porém de maneira escalonada, de forma que cada curso fosse chamado para o exame a cada três anos. Eram avaliados os alunos que cursavam o primeiro ano e também os alunos concluintes, desde que tivessem cumprido mais de $80 \%$ da carga horária mínima do curso. Desde a sua criação até a data do levantamento deste artigo, foram realizados oito exames nacionais, seguindo uma lógica avaliativa pelas áreas do conhecimento: primeiro, os cursos de saúde, ciências agrárias e áreas afins; segundo, as ciências exatas, licenciaturas e áreas afins; terceiro, as ciências sociais aplicadas, ciências humanas e áreas afins (BRITO, 2008). 
O processo de implantação do Sinaes passou por profundas mudanças, a partir de 2007, com a criação de dois índices: o Conceito Preliminar de Curso (CPC) e o Índice Geral de Cursos (IGC), conforme o Art. $34 \$ 1^{\circ}$ da Portaria Normativa № 40, de 12 de dezembro de 2007. Esses índices, que têm como um dos indicadores os resultados do Enade ${ }^{3}$, geraram uma classificação entre as Instituições de Ensino Superior divulgada pelo próprio Ministério da Educação (MEC), fazendo voltar à cena nacional os rankings, amplamente disseminados pelo ENC (POLIDORI, 2009).

Em 2009, o Enade passou a ser universal e não mais amostral, ou seja, todos os alunos, ingressantes e concluintes dos cursos de graduação que fizeram parte da área avaliada naquele ano, fizeram a prova. Essa mudança fez que o Enade retomasse os moldes do ENC, que tinha um caráter censitário.

Em 2011, aconteceu nova mudança, todos os ingressantes foram dispensados da prova. Com isso, teoricamente, eliminava-se importante diferencial do Enade com relação ao exame anterior, o ENC, pois uma das bandeiras levantadas pelo Sinaes, por meio do Enade, era a identificação do valor agregado da IES na formação do aluno, tomando como referência a avaliação do seu desempenho na entrada e na saída do curso. Entretanto, para o governo, essa análise não procede, já que o diferencial do Enade, em relação ao ENC, se manteria inalterado, uma vez que, se por uma lado, elimina-se a prova dos ingressantes, por outro, a comparação para a obtenção do valor agregado passou a ser feita com base na nota do Exame Nacional do Ensino Médio (Enem).

Dentro desse breve contexto, o presente artigo se debruça na compreensão da produção do conhecimento sobre o Enade, a partir do mapeamento da produção científica brasileira sobre esse instrumento de avaliação, tomando como referência teses de doutorado e dissertações de mestrado defendidas no Brasil, entre 2004 e 2010. Apresenta os resultados de uma pesquisa essencialmente de cunho bibliográfica, do tipo Estado da Arte, a mesma

\footnotetext{
${ }^{3}$ Convém ressaltar que esses índices resultam da combinação de uma série de indicadores, além do desempenho no Enade, por exemplo, conforme dados oficiais (BRASIL, 2009), o CPC combina diversas medidas relativas à qualidade do curso, tais como: informações de infraestrutura e instalações físicas, recursos didático-pedagógicos e corpo docente; o desempenho obtido pelos estudantes concluintes e ingressantes no Enade ; e os resultados do Indicador da Diferença entre os Desempenhos Esperado e Observado (IDD).
} 
que se caracteriza por realizar um balanço da área do conhecimento escolhida pelo pesquisador, com a finalidade de diagnosticar temas de relevância, assuntos emergentes e tendências do conhecimento científico (FERREIRA, 2002). Esse tipo de pesquisa permite identificar e inventariar a produção científica de um determinado espaço de tempo, bem como analisar, categorizar e também revelar diferentes enfoques e facetas, servindo de fontes de informação para consulta da comunidade científica e para direcionamento de pesquisas e compreensão de processo e fenômenos educacionais (TEIXEIRA, 2006).

Inicialmente, foram analisados os títulos e resumos das teses e dissertações. Entende-se o resumo aqui como um gênero discursivo institucionalizado no ambiente acadêmico, com estrutura de informações e intenções fundamentais, referentes aos trabalhos no qual estão inseridos. Cabe ainda destacar que os resumos das pesquisas não foram a única fonte de informação, sempre que necessário, analisaram-se as introduções e conclusões dos trabalhos selecionados. Devem-se registrar os cuidados tomados em relação às limitações existentes na realização desse tipo de pesquisa bibliográfica que, conforme Calderón e Ferreira (2011), entre outras limitações, podem ser citadas: títulos que não refletem necessariamente o conteúdo do texto, o caráter extremamente abrangente e genérico das palavras-chave, a subjetividade no enquadramento dos textos numa determinada categoria, entre outros.

\section{Número de teses, linha do tempo e área do conhecimento}

No intuito de identificar o número de dissertações de mestrado e teses de doutorado sobre o Enade, foram feitas buscas em dois bancos de dados nacionais: o Banco de Teses da Coordenação de Aperfeiçoamento de Pessoal de Nível Superior (Capes) e a Biblioteca Digital Brasileira de Teses e Dissertações. Nessas buscas, foram utilizadas duas palavras chaves - Enade e Exame Nacional de Desempenho de Estudantes. Foram encontrados e separados 62 estudos, em nível de mestrado, mestrado profissionalizante ou doutorado. Após a leitura dos títulos e resumos das referidas obras, foram descartados 30 estudos pelo fato de abordarem o Enade de forma tangencial, restando, dessa forma, 32 que serviram de base para o presente estudo.

No gráfico 1, pode-se identificar a linha do tempo da produção científica, ou seja, a distribuição dos estudos a partir do ano em que foram defendidos. 
Constatou-se que o auge da produção de estudos sobre o Enade se deu em 2009, ano em que foram defendidos doze trabalhos, começando um declínio a partir de 2010, quando o número de estudos caiu para quatro.

\section{GRÁFICO 1}

Quantidade por ano de defesa das teses e/ou dissertações produzidas sobre o Enade

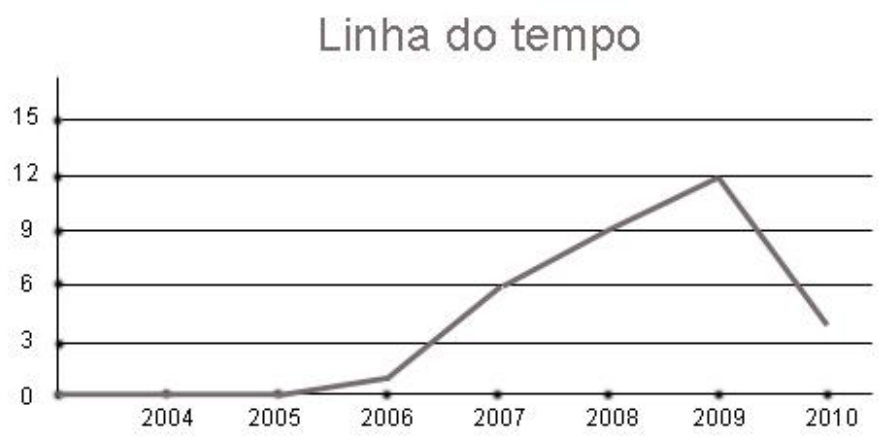

A pesquisa permitiu identificar a área do conhecimento na qual está inserida cada um dos estudos selecionados, revelando que a avaliação da educação superior é uma temática essencialmente multidisciplinar, ou seja, abordada por diversas áreas do conhecimento. A tabela 1 permite constatar a predominância de estudos em nível de pós-graduação na área das ciências humanas, com 62,5\%, com expressiva produção em outras áreas do conhecimento, como ciências econômicas e administrativas (15,65\%), ciências exatas $(12,5 \%)$ e ciências da saúde $(9,35 \%)$.

\section{TABELA 1}

Teses e dissertações defendidas no Brasil em Programas de Pós-Graduação sobre o Enade, entre 2004 e 2010, distribuídas por áreas de concentração.

\begin{tabular}{l|c|c}
\hline \multicolumn{1}{c|}{ ÁREA DE CONCENTRAÇÃo } & QUANTIDADE & PORCENTAGEM \\
\hline Ciências Humanas & & $62,50 \%$ \\
\hline Educação & 18 & $56,25 \%$ \\
\hline Linguística & 1 & $3,12 \%$ \\
\hline Educação Física & 2 & $3,12 \%$ \\
\hline Ciências Econômicas e Administrativas & 2 & $15,65 \%$ \\
\hline Administração de Empresas & 1 & $6,26 \%$ \\
\hline Contabilidade/Ciências Contábeis & & $6,26 \%$ \\
\hline Políticas Públicas e gestão da educação superior & 2 & $3,12 \%$ \\
\hline Ciência Exatas & 1 & $12,50 \%$ \\
\hline Engenharia Elétrica & 1 & $6,26 \%$ \\
\hline Ciências Exatas / Matemática & & $3,12 \%$ \\
\hline Ensino de Ciências e Matemática & 3 & $3,12 \%$ \\
\hline Ciências da Saúde & $\mathbf{3 2}$ & $9,35 \%$ \\
\hline Psicologia & & $\mathbf{9 , 3 5 \%}$ \\
\hline Total & & $\mathbf{1 0 0 \%}$ \\
\hline
\end{tabular}


$\mathrm{Na}$ área das ciências humanas, predominam estudos realizados em programas de pós-graduação em educação, com 56,25\%, seguida por linguística e educação física, com 3,12\% cada. No âmbito das ciências econômicas e da administração, foram realizados estudos produzidos na área de administração de empresas, com 6,26\%, e contabilidade, com 6,26\%, além de políticas públicas e gestão da educação superior, com 3,12\%. Nas ciências exatas, enquadram-se estudos em engenharia elétrica (6,26\%), matemática e ensino de ciências e matemática, com 3,12\%, cada. Por último, nas ciências da saúde, o Enade tornou-se foco de estudo da área de psicologia, com três estudos que somam $9,37 \%$.

\section{Instituições e produtores do conhecimento}

$\mathrm{Na}$ pesquisa realizada, identificaram-se três dissertações em nível de mestrado profissionalizante, perfazendo 9,4\%. A maioria dos estudos ficou no âmbito do mestrado acadêmico, com $65,6 \%$, enquanto a soma de doutorados defendidos totalizou 25\%. Ao todo, somaram-se 21 dissertações em nível de mestrado acadêmico ${ }^{4}$, oito teses de doutorado ${ }^{5}$ e três de mestrado profissionalizante.

Outro dado relevante sobre a temática do Enade foi a distribuição regional das teses e dissertações defendidas no Brasil, entre 2004 e 2010. Constata-se que a região sudeste assume papel predominante, com 59,5\% das teses e dissertações, sendo seguida pelas regiões nordeste e centro-oeste, com 18,7\%, cada, do total de estudos produzidos. A região sul aparece com um trabalho, equivalente a $3,1 \%$.

O maior número de trabalhos foi localizado na região sudeste, em universidades do estado de São Paulo: Pontifícia Universidade Católica de São Paulo (PUC-SP), Universidade São Francisco (USF) e Universidade Estadual de Campinas (Unicamp). A Tabela 3 mostra a significativa produção de duas

\footnotetext{
${ }^{4}$ Autores das dissertações em nível de mestrado: Alvarães (2009); Alves (2007); Antunes (2008); Bastos (2007); Borges (2009); Campos (2009a); Campos (2009b); Del rio (2008); Eussen (2010); Gonçalves (2009); Nogueira (2008); Oliveira (2006). Pereira (2010); Polizel (2009); Reis (2009); Rodrigues (2008); Santana (2009); Sheremetieff (2008); Silva (2007); Silva (2009); Souza (2006); Souza (2009); Souza (2010); Veiga (2009).

${ }_{5}$ Autores doutorado: Aragão (2008); De Lara (2007); Fonseca (2008); Gracioso (2008); Moreira (2010); Perim (2007); Sousa (2009); Souza (2007).
} 
universidades fora do eixo São Paulo-Rio de Janeiro: a Universidade de Brasília (UnB), da região centro-oeste, com três trabalhos, e a Universidade Federal do Ceará (UFC), da região nordeste, com dois trabalhos. A pesquisa permite constatar a existência de duas universidades que se destacaram por produzir, cada uma delas, o maior número de estudos sobre o Enade, a USF e a UnB.

\section{TABELA 3}

Teses de mestrado e doutorado produzidas em torno do Enade, por região do Brasil e por universidades (2004-2010).

\begin{tabular}{|c|c|c|}
\hline Região / Universidades & $\begin{array}{c}\text { Quanti } \\
\text { dade }\end{array}$ & $\%$ \\
\hline \multicolumn{3}{|l|}{ REGIÃO SUL } \\
\hline Universidade Federal do Rio Grande do Sul & 1 & $3,1 \%$ \\
\hline \multicolumn{3}{|l|}{ REGIÃO SUDESTE } \\
\hline Centro Universitário do Triângulo & 1 & $3,1 \%$ \\
\hline Fundação Getúlio Vargas & 1 & $3,1 \%$ \\
\hline $\begin{array}{l}\text { Fundação Instituto Capixaba de Pesq. em Cont. Econ. e } \\
\text { Finanças }\end{array}$ & 1 & $3,1 \%$ \\
\hline Pontifícia Universidade Católica - São Paulo & 2 & $6,4 \%$ \\
\hline Universidade Católica de Petrópolis & 2 & $6,4 \%$ \\
\hline Universidade de São Paulo/Ribeirão Preto & 1 & $3,1 \%$ \\
\hline Universidade São Francisco & 3 & $9,3 \%$ \\
\hline Universidade Estadual de Campinas & 2 & $6,4 \%$ \\
\hline Universidade Federal de Minas Gerais & 1 & $3,1 \%$ \\
\hline Universidade Federal de São Carlos & 1 & $3,1 \%$ \\
\hline Universidade São Marcos & 1 & $3,1 \%$ \\
\hline Universidade Cruzeiro do Sul & 1 & $3,1 \%$ \\
\hline Universidade Gama Filho & 1 & $3,1 \%$ \\
\hline Universidade do Vale do Rio dos Sinos & 1 & $3,1 \%$ \\
\hline \multicolumn{3}{|l|}{ REGIÃO CENTRO OESTE } \\
\hline Universidade Católica de Brasília & 1 & $3,1 \%$ \\
\hline Pontifícia Universidade Católica - Goiás & 1 & $3,1 \%$ \\
\hline Universidade de Brasília & 3 & $9,4 \%$ \\
\hline Universidade Federal de Goiás & 1 & $3,1 \%$ \\
\hline \multicolumn{3}{|l|}{ REGIÃO NORDESTE } \\
\hline Universidade Federal do Maranhão & 1 & $3,1 \%$ \\
\hline Universidade Federal de Alagoas & 1 & $3,1 \%$ \\
\hline Universidade Federal do Ceará & 2 & $6,3 \%$ \\
\hline Universidade Federal do Rio Grande do Norte & 1 & $3,1 \%$ \\
\hline Universidade Federal da Paraíba/João Pessoa & 1 & $3,1 \%$ \\
\hline Total & 32 & 100 \\
\hline
\end{tabular}

No que se refere aos principais orientadores de dissertações e/ou teses sobre o tema Enade, a tabela 4 permite constatar o destaque que obteve Claudette Maria Medeiros Vendramini, Bolsa de Produtividade em Pesquisa do CNPq (PQ), da UFS, que orientou Oliveira (2006), Nogueira (2008) e Veiga (2009), todos na linha da Psicologia da Construção, Validação e Padronização de Instrumentos de Medida. Ela é seguida por Wagner Bandeira Andriola, da UFC, (PQ), que orientou dois trabalhos: Souza (2009) e Campos (2009), ambos dentro da linha de pesquisa: Avaliação da Qualidade de Instituições de Ensino. 
Feita uma busca em todos os currículos dos 29 orientadores constantes na Plataforma Lattes ${ }^{6}$, constatou-se elevada aderência entre a linha de pesquisa do orientador e o estudo orientado, $83 \%$ das teses e dissertações encontram-se de acordo com a linha de pesquisa dos respectivos orientadores e $17 \%$ têm uma aderência parcial.

\section{TABELA 4}

Os orientadores, a quantidade de teses, o financiamento, suas respectivas universidades e a aderência da tese ou dissertação com a linha da pesquisa do orientador.

\begin{tabular}{|c|c|c|c|c|c|}
\hline Nome do Orientador & $\begin{array}{c}\text { Teses e/ou } \\
\text { Disserta } \\
\text { ções } \\
\end{array}$ & $\begin{array}{c}\text { Bolsista } \\
\text { Produtivida } \\
\text { de CNPq }\end{array}$ & $\begin{array}{c}\text { Instituição de Educação } \\
\text { Superior }\end{array}$ & $\begin{array}{l}\text { Programa de } \\
\text { Pós Graduação }\end{array}$ & $\begin{array}{c}\text { Aderência } \\
\text { com a tese } \\
\text { orientada }\end{array}$ \\
\hline $\begin{array}{l}\text { VENDRAMINI, Claudette } \\
\text { Maria Medeiros }\end{array}$ & 3 & SIM & Universidade São Francisco & Psicologia & Total \\
\hline $\begin{array}{l}\text { ANDRIOLA, Wagner } \\
\text { Bandeira }\end{array}$ & 2 & SIM & $\begin{array}{l}\text { Universidade Federal do } \\
\text { Ceará }\end{array}$ & Educação & Total \\
\hline ALMEIDA, Maria de Fátima & 1 & NÃO & $\begin{array}{l}\text { Universidade Federal da } \\
\text { Paraíba/João Pessoa }\end{array}$ & Linguística & Total \\
\hline AMARAL, Luiz Henrique & 1 & NÃO & Universidade Cruzeiro do Sul & $\begin{array}{c}\text { Ensino de Ciências } \\
\text { Matemáticas }\end{array}$ & Total \\
\hline $\begin{array}{l}\text { ARANHA FILHO, Francisco } \\
\text { José Espósito }\end{array}$ & 1 & NÃO & Fundação Getúlio Vargas & $\begin{array}{l}\text { Administração de } \\
\text { Empresa }\end{array}$ & Total \\
\hline $\begin{array}{l}\text { ARAUJO, Adriana Maria } \\
\text { Procópio de }\end{array}$ & 1 & SIM & $\begin{array}{l}\text { Universidade de São } \\
\text { Paulo/Ribeirão Preto }\end{array}$ & $\begin{array}{c}\text { Controladoria e } \\
\text { Contabilidade }\end{array}$ & Total \\
\hline $\begin{array}{l}\text { BRITO DIAS, Márcia } \\
\text { Regina Ferreira de }\end{array}$ & 1 & SIM & $\begin{array}{l}\text { Universidade Estadual de } \\
\text { Campinas }\end{array}$ & Educação & Total \\
\hline BRITO, Leonardo da Cunha & 1 & NÃO & $\begin{array}{l}\text { Universidade Federal de } \\
\text { Goiás }\end{array}$ & $\begin{array}{l}\text { Engenharia Elétrica } \\
\text { e de Computação }\end{array}$ & Total \\
\hline BRZEZINSKI, Iria & 1 & SIM & PUC - Goiás & Educação & Total \\
\hline $\begin{array}{l}\text { CAPPELLETTI, Isabel } \\
\text { Franchi }\end{array}$ & 1 & NÃO & PUC - São Paulo & $\begin{array}{l}\text { Educação } \\
\text { (Currículo) }\end{array}$ & Total \\
\hline $\begin{array}{l}\text { CASTRO, Alda Maria } \\
\text { Duarte Araújo }\end{array}$ & 1 & NÃO & $\begin{array}{l}\text { Universidade Federal do Rio } \\
\text { Grande do Norte }\end{array}$ & Educação & Total \\
\hline $\begin{array}{l}\text { CAVALCANTE, Maria do } \\
\text { Socorro Aguiar de Oliveira }\end{array}$ & 1 & NÃO & $\begin{array}{l}\text { Universidade Federal de } \\
\text { Alagoas }\end{array}$ & Educação & Total \\
\hline $\begin{array}{l}\text { FORSTER, Mari Margarete } \\
\text { dos Santos }\end{array}$ & 1 & NÃO & $\begin{array}{l}\text { Universidade do Vale do Rio } \\
\text { dos Sinos }\end{array}$ & Educação & Total \\
\hline LABIDI, Sofiani & 1 & NÃO & $\begin{array}{l}\text { Universidade Federal do } \\
\text { Maranhão }\end{array}$ & $\begin{array}{l}\text { Engenharia de } \\
\text { eletricidade }\end{array}$ & Parcial \\
\hline $\begin{array}{l}\text { LEITE, Denise Balarine } \\
\text { Cavalheiro }\end{array}$ & 1 & SIM & $\begin{array}{l}\text { Universidade Federal do Rio } \\
\text { Grande do Sul }\end{array}$ & Educação & Total \\
\hline LEITE, Lígia Silva & 1 & NÃO & $\begin{array}{l}\text { Universidade Católica de } \\
\text { Petrópolis }\end{array}$ & Educação & Total \\
\hline $\begin{array}{l}\text { LUSTOSA, Paulo Roberto } \\
\text { Barbosa }\end{array}$ & 1 & NÃO & Universidade de Brasília & Contabilidade & Total \\
\hline MANRIQUE, Ana Lúcia & 1 & NÃO & PUC - São Paulo & $\begin{array}{l}\text { Educação } \\
\text { Matemática }\end{array}$ & Total \\
\hline PAGOTTI, Antônio Wilson & 1 & NÃO & $\begin{array}{l}\text { Centro Universitário do } \\
\text { Triângulo } \\
\end{array}$ & Educação & Parcial \\
\hline $\begin{array}{l}\text { PEIXOTO, Maria do Carmo } \\
\text { de Lacerda }\end{array}$ & 1 & NÃO & $\begin{array}{l}\text { Universidade Federal de } \\
\text { Minas Gerais }\end{array}$ & Educação & Total \\
\hline $\begin{array}{l}\text { SEGENREICH, Stella } \\
\text { Cecília Duarte }\end{array}$ & 1 & NÃO & $\begin{array}{l}\text { Universidade Católica de } \\
\text { Petrópolis }\end{array}$ & Educação & Parcial \\
\hline SILVA JUNIOR, Annor da & 1 & NÃO & $\begin{array}{l}\text { Fund. Instituto Capixaba de } \\
\text { Pesq. Em Cont. Econ. e } \\
\text { Finanças } \\
\end{array}$ & $\begin{array}{l}\text { Administração de } \\
\text { Empresa }\end{array}$ & Total \\
\hline $\begin{array}{l}\text { SOARES, Antônio Jorge } \\
\text { Gonçalves }\end{array}$ & 1 & SIM & Universidade Gama Filho & Educação Física & Total \\
\hline SOBRINHO, José Dias & 1 & NÃO & $\begin{array}{l}\text { Universidade Estadual de } \\
\text { Campinas }\end{array}$ & Educação & Total \\
\hline SOUSA, José Vieira de & 1 & $\mathrm{NÃO}$ & Universidade de Brasília & Educação & Total \\
\hline
\end{tabular}

\footnotetext{
${ }^{6}$ Ver em: http://lattes.cnpq.br
} 


\begin{tabular}{l|c|c|l|c|c}
\hline $\begin{array}{l}\text { TANCREDI, Regina Maria } \\
\text { Simões Puccinelli }\end{array}$ & 1 & NÃO & $\begin{array}{l}\text { Universidade Federal de São } \\
\text { Carlos }\end{array}$ & Educação & Parcial \\
\hline $\begin{array}{l}\text { TRISTÃO, José Américo } \\
\text { Martelli }\end{array}$ & 1 & NÃO & Universidade São Marcos & $\begin{array}{c}\text { Educação, } \\
\text { Administração e } \\
\text { Comunicação }\end{array}$ & Total \\
\hline VELLOSO, Jacques Rocha & 1 & NÃO & Universidade de Brasília & Educação & Parcial \\
\hline WALKER, Robert Kenyon & 1 & NÃO & $\begin{array}{l}\text { Universidade Católica de } \\
\text { Brasília }\end{array}$ & Educação & Total \\
\hline
\end{tabular}

\section{Eixo e tendências temáticas}

Os autores dos estudos analisados apresentam alguns interesses acadêmicos comuns quanto a determinados aspectos do Enade. Assim sendo, foram encontrados pesquisadores que abordam os impactos que o Enade provoca no desempenho das IES e outros que revelam projetos para a melhoria dos cursos. Alguns abordam o Enade como parte de uma política pública avaliativa, reafirmando a importância de uma política de avaliação; outros vão atrás da correlação que o referido exame tem com a formação dos professores, apontando pistas para se chegar ao professor ideal. Há também aqueles que analisam os aspectos técnicos do Enade, abordando a Teoria da Resposta, enquanto outros se preocupam com as didáticas de ensino e a preocupação da influencia do Enade na definição curricular dos cursos.

Conforme a Tabela 5, foram oito os eixos temáticos identificados, podendose notar uma maior incidência de trabalhos preocupados com o aprimoramento do desempenho das IES, tanto no âmbito do desempenho institucional (19\%), quanto no âmbito dos cursos de graduação (15,5\%), totalizando $34,5 \%$.

\section{TABELA 5}

Eixos temáticos predominantes nas teses e dissertações em torno do tema Enade

\begin{tabular}{l|c|c}
\hline EIXOS TEMÁTICOS & QUANTIDADE & PORCENTAGEM \\
\hline Melhorias do desempenho institucional & 6 & $19 \%$ \\
\hline Melhorias dos cursos de graduação & 5 & $15,5 \%$ \\
\hline Fatores de desempenho do aluno & 5 & $15,5 \%$ \\
\hline Política pública avaliativa & 5 & $15,5 \%$ \\
\hline Aspectos técnicos e operacionais & 4 & $12,5 \%$ \\
\hline Estratégias didáticas para a melhoria do desempenho do aluno & 3 & $9,5 \%$ \\
\hline Formação de professores & 3 & $9,5 \%$ \\
\hline Indução de transformações curriculares & 1 & $3 \%$ \\
\hline Total & $\mathbf{3 2}$ & $\mathbf{1 0 0} \%$ \\
\hline
\end{tabular}

Num segundo momento, pode-se agrupar dois eixos preocupados com o desempenho dos alunos participantes do Enade: fatores de desempenho do aluno 
$(15,5 \%)$ e estratégias didáticas para a melhoria do desempenho do aluno $(9,5 \%)$. Esses dois eixos perfazem um total de $25 \%$ dos estudos.

Num terceiro momento, destacam-se estudos que discutem o Enade como política pública avaliativa, com 15,5\%. Na sequência, e seguindo a lógica de quantidade de estudos que aparecem sobre cada eixo, encontram-se estudos que enfocam aspectos técnicos e operacionais, com 12,5\%. Finalizando, com dois eixos, o Enade e sua correlação com a formação de professores, que aparece com $9,5 \%$, e o potencial do Enade em transformar currículos, 3\%.

\subsection{Melhoria do desempenho institucional}

Este eixo identifica seis trabalhos que colocam o Enade como um fator que desencadeia ações para a busca de melhorias no desempenho das IES, com um foco prioritário em estudos de casos em universidades federais.

Quatro das seis dissertações foram realizadas na região nordeste, sendo duas na UFC. Souza (2009) analisou a cultura avaliativa na UFC, tendo como base as representações sociais dos diversos segmentos das unidades acadêmicas que participaram do Ciclo de Avaliação Institucional 2005 e 2006 e do Enade 2008. Procurou compreender que representações os alunos e coordenadores dos cursos têm do Enade e qual o grau de conhecimento sobre o Sinaes, mostrando que as representações dos gestores, coordenadores, técnicos administrativos e alunos apresentam especificidades em relação à inserção social e aos interesses de cada segmento. Campos (2009) abordou os efeitos do Enade sobre a IES, identificando os fatores associados à eficácia educacional, por meio da visão dos coordenadores dos cursos de graduação, que contribuíram para a melhoria do desempenho global dos cursos da UFC. O autor constatou uma relação direta entre a eficácia da IES e os resultados dos exames do Enade.

O estudo de Eussen (2010) analisou a configuração que a política nacional de avaliação vem assumindo na Universidade Federal do Rio Grande do Norte (UFRN) e discute o uso dos instrumentos de avaliação para o ensino superior no contexto da reforma do Estado, que passou a promover e mensurar a qualidade das IES, com base nos valores da excelência e da competitividade. Eussen (2010) comprovou que a UFRN vem implantando o Sinaes de forma gradual e que a busca da qualidade tem promovido a reflexão sobre o Enade. 
Da Universidade Federal do Maranhão (UFMA), vem o estudo de Pereira (2010), que discute a necessidade de as IES se adequarem a procedimentos de avaliação dentro dos moldes do Enade. $O$ autor propõe a automação da correção dos quesitos do Enade, utilizando os princípios do software UML 2.0, agregando agilidade na entrega dos resultados.

Com o objetivo de analisar as contribuições do Enade para o aperfeiçoamento dos cursos de graduação, tendo a Universidade Federal de Minas Gerais como referência para seus estudos, Rodrigues (2008), a partir de entrevistas semiestruturadas com coordenadores e ex-coordenadores do setor de avaliação da referida universidade, evidenciou um hiato entre procedimentos institucionais e os diagnóstico oferecidos pelo Enade, revelando a necessidade dessa IES de aprimorar os cursos, considerando os resultados dessa avaliação externa.

Analisando como a representatividade do Enade influencia os fatores críticos de sucesso relacionados à gestão do conhecimento em uma IES privada, Polizel (2009), usando entrevistas semiestruturadas e observação não participante, concluiu que, entre os fatores críticos de sucesso, as políticas educacionais e a avaliação institucional são consideradas as mais relevantes para as IES.

\subsection{Melhoria dos cursos de graduação}

Os cinco trabalhos constantes neste eixo abordam o Enade como um exame em larga escala, que pode levar melhorias aos cursos de graduação, abordando os mais variados cursos, como administração de empresas, pedagogia, educação física, nutrição e física. O Enade é visto como um instrumento "deflagrador de alterações", de "mudanças significativas" e que presta "grandes contribuições" para as IES e seus cursos.

Abordando o processo de avaliação das IES no triângulo mineiro, a partir do Enade do ano de 2004, Alves (2007) analisa a configuração dos cursos de nutrição, a partir de uma revisão bibliográfica, conseguindo identificar em que pontos existem falhas a serem melhoradas no curso de nutrição de duas IES. Procurando compreender as influências do Enade na dinâmica dos processos avaliativos do curso de educação física, do Instituto Porto Alegre, da Igreja Metodista do Rio Grande do Sul, Fonseca (2008) verifica mudanças significativas 
nas dinâmicas de aulas e também a implantação de novas estratégias para avaliações internas do referido curso.

Gracioso (2008) aborda variáveis que ajudem a explicar o desempenho de formandos, nos cursos de graduação de administração de empresas, a partir do ENC e Enade, chegando a apontar três variáveis: uso de microcomputadores pelos alunos, competências desenvolvidas ao longo do curso e domínio da língua inglesa. Reis (2009), por sua vez, abordou a avaliação institucional nos cursos de física da UnB e da Universidade Católica de Brasília (UCB), com a finalidade de investigar possíveis mudanças ocorridas na gestão desses cursos, em decorrência dos resultados obtidos no Enade. Para esse autor, o Enade presta grande contribuição para a melhoria da qualidade educacional, mas traz um certo tensionamento, na medida em que abriu a possibilidade de classificar as instituições, por meio de ranqueamento.

De forma a verificar as repercussões do Enade no projeto políticopedagógico do curso de pedagogia da UniEvangélica, Campos (2009) constata que a avaliação institucional tem sido o principal instrumento para deflagrar as alterações no projeto político-pedagógico do curso de pedagogia, e que, apesar das tendências centralizadoras e reguladoras, os atores educacionais têm sido ouvidos e têm conseguido alguns avanços na concepção de uma educação emancipatória.

\subsection{Fatores de desempenho do aluno}

Neste eixo temático, cinco trabalhos abordam o desempenho dos alunos nos mais diferentes cursos, conjugado com variados focos interpretativos. Todos os estudos, três doutorados e dois mestrados, usaram dados do Enade para suas pesquisas, focando fatores de desempenho dos alunos em seus respectivos cursos.

Antunes (2008), utilizando a Técnica Delphi (processo de resumo e revisão de um questionário aplicado a um grupo amostral) e comparando os resultados com a avaliação do Enade 2004, identificou os aspectos que interferiram na qualidade do processo de formação acadêmica do curso de educação física do Centro Universitário da Cidade. Antunes concluiu que fatores institucionais declarados como negativos não foram considerados determinantes na formação do aluno. 
Usando o resultado do Enade 2006 para o curso de ciências contábeis, Souza (2008) objetivou, em sua dissertação, identificar variáveis na relação entre o desempenho dos alunos e sua situação socioeconômica. Sua metodologia foi empírico-analítica, tendo como instrumento a análise de regressão multivariada. Sua conclusão é que o nível de formação do aluno anterior ao seu ingresso em uma IES é a variável de maior influência no desempenho dos cursos.

Moreira (2010) pesquisou a influência de fatores institucionais sobre o rendimento de estudantes concluintes dos cursos de biologia, engenharia civil, história e pedagogia no Enade 2005. Usando dois modelos para analisar os dados, regressão múltipla e a árvore de classificação, constatou que a influência de fatores institucionais sobre o rendimento dos estudantes não é homogênea e que se altera conforme a categoria administrativa e a organização acadêmica da IES.

Perim (2007), usando dados do Enade 2004, referentes aos estudantes de medicina, fez uma análise comparativa entre o desempenho dos estudantes da Universidade Estadual de Londrina e outras escolas de medicina que utilizavam metodologias semelhantes e diferentes. Os resultados demonstraram que 0 desempenho dos alunos da UEL superou a média dos grupos estudados de outras faculdades.

As relações entre o desempenho no Enade e o raciocínio de 141 estudantes ingressantes e concluintes do curso de ciência da computação da Faculdade de Administração Espírito Santenses, foi o tema da tese de Souza (2007). Para tal estudo, foram utilizados problemas matemáticos e entrevistas. Souza chegou à comprovação de que os desempenhos no Enade estavam relacionados ao desempenho em nível acadêmico.

\subsection{Política pública avaliativa}

Neste eixo, no qual foram enquadrados cinco estudos, se discute o Enade como parte de uma política pública de avaliação. Há uma característica comum encontrada nas dissertações e teses analisadas: todas elas fazem alusões e comparações com o Exame Nacional de Cursos (ENC), conhecido como Provão. O Enade é entendido pelos autores como uma continuação do Provão ou, como um desdobramento de uma nova política pública de avaliação educacional. 
A reforma neoliberal da Universidade no Brasil é o tema da dissertação de Bastos (2007), que faz a análise dos discursos dos ministros da educação da era Lula, Cristóvam Buarque, Tarso Genro e Fernando Haddad, acerca de medidas relacionadas ao Prouni, ao Sinaes e ao Enade. Bastos conclui que, travestidas de modernas e inovadoras, essas políticas públicas se sustentam numa ideologia de acomodação e ajuste do modelo educacional funcional ao capital, numa sociedade periférica, no mundo da propalada pós-modernidade.

A dissertação de Silva (2007) analisa e compara as políticas de avaliação da educação superior centradas no ENC de 2002 e 2003 e no Enade 2004, por meio das provas dos cursos de medicina e de enfermagem. Silva se detém no conteúdo valorizado nos aspectos hospitalocêntricos ou holísticos, evidencia mudanças nas questões do curso de enfermagem e nenhuma mudança nos exames do curso de medicina.

Aragão (2008) aborda os cursos de graduação em administração de empresas, tendo como objetivo saber se as políticas de avaliação do governo geram melhorias nos mesmos. Essa pesquisa aborda o ENC e o Enade, utilizando estudos de caso múltiplos, destacando a relevância das políticas de avaliação, além de mostrar as dificuldades e limites de aplicação do conceito de qualidade ao contexto educacional.

Del Rio (2008) analisa as bases teóricas das políticas públicas para o ensino superior privado, com ênfase em sistemas de avaliação. Não faz aqui somente uma comparação do Enade com o Provão, mas aborda políticas anteriores, como o Programa de Avaliação da Reforma Universitária (PARU) e o Programa de Avaliação Institucional das Universidades Brasileiras (Paiub). Del Rio vê uma assimetria entre o profissional formado no segmento privado e o papel que as IES representam na crescente demanda do mercado de trabalho.

Analisando os cursos jurídicos, Sheremetieff (2008) destaca o Provão, o Enade e o exame da Ordem dos Advogados do Brasil (OAB) como avaliações externas e estratégicas para a manutenção da qualidade do ensino nos cursos jurídicos, discute as diretrizes curriculares interpretadas por profissionais da área jurídica e como os professores do curso de direito da Universidade Católica de Petrópolis interpretam as avaliações realizadas pelo Enade e pela OAB. 


\subsection{Aspectos técnicos e operacionais}

Os quatro estudos deste eixo fazem uso do Enade em seu aspecto técnico, coletando informações das provas para uma modelagem estatística. Das quatro dissertações de mestrado, três são da área de psicologia (OLIVEIRA, 2006; NOGUEIRA, 2008 e VEIGA, 2009) e uma de linguística (SILVA, 2009), sendo as três de psicologia elaboradas na USF.

O estudo de Silva (2009) versou sobre a abordagem de gêneros do discurso em questões do Enade 2006, aplicadas aos estudantes dos cursos de administração, psicologia e secretariado executivo. Constatou-se que existe uma defasagem entre o que é pedido, em termos de gênero discursivo no Enade, e o que é exigido na prática dos profissionais.

Três estudos adotaram uma modelagem estatística para avaliar habilidades e conhecimentos, denominada de Teoria da Resposta ao Item (TRI), nas questões do Enade. Oliveira (2006) analisou as propriedades psicométricas do Enade por meio da TRI, usando o banco de dados com os resultados do exame no ano de 2004, de estudantes de medicina de todo o país. Comprovou que as provas apresentam maior informação - sendo, portanto, voltadas para um nível de habilidade mais elevado - no componente de formação específica, se comparada com componentes de formação geral. Nogueira (2008) aplicou a TRI para avaliar as questões de formação geral da prova do Enade 2004 e 2005, mais especificamente as questões que envolviam dados estatísticos, coletando informações de 403.512 estudantes. Nogueira visou à contribuição do construto inteligência no desempenho acadêmico e constatou que as questões discursivas do Enade apresentam um parâmetro de dificuldade mais baixo e não equiparável. Finalizando, Veiga (2009) realizou uma análise, usando a TRI mediante o método Rasch, utilizando informação de 49.497 estudantes e relacionando as habilidades e competências por eles adquiridas. Constatou que a prova do Enade engloba todas as habilidades necessárias para a boa formação do pedagogo.

\subsection{Estratégias didáticas para a melhoria do desempenho do aluno}

Neste eixo, evidenciam-se estratégias que visam a melhorar o rendimento dos alunos, por meio de técnicas para auxiliar o aprendizado. Alvarães (2009) abordou os mapas conceituais como prática pedagógica para a formação geral dos alunos do curso de administração de empresas de uma IES do Rio de 
Janeiro, utilizando resultados do Enade. O uso de sistemas de tutores inteligentes na compreensão de leitura foi o tema de Borges (2009), com o intuito de desenvolver uma técnica para auxiliar na análise de textos acadêmicos. Gonçalves (2009), por sua vez, objetivou desenvolver uma estratégia de ensino de trigonometria, utilizando a Tecnologia da Informação e Comunicação para verificar o êxito dessa estratégia no processo de aprendizagem, partindo do grau de incidência nas questões de exames oficiais, incluindo-se aí, o Enade.

\subsection{Formação de professores}

Os três estudos que compõem este eixo temático abordam o perfil e as exigências para a atuação dos professores nos cursos superiores, agentes principais para a mudança e melhoria do ensino.

De Lara (2007) abordou o Enade como constitutivo de um padrão de normalidade para se produzir o professor de matemática ideal, adequado ao contexto da globalização e da sociedade da informação. Santana (2009), em sua dissertação de mestrado acadêmico, buscou os atributos e saberes necessários para se tornar um bom professor de ciências contábeis nas IES federais, a partir da percepção de coordenadores de cursos de ciências contábeis. Souza (2010), com a utilização de dados do Enade, procurou compreender a realidade dos cursos de matemática e pedagogia da PUC-SP e também da Universidade Federal do Mato Grosso (UFMT), traçando um perfil do docente e suas motivações, por meio de um questionário socioeconômico.

\subsection{Indutor de transformações curriculares}

O estudo de Sousa (2009), o único enquadrado nesta categoria, objetivou compreender o Sinaes como política pública, na perspectiva de identificar o seu potencial em transformar o currículo das universidades. Partindo de pesquisa documental, depoimentos e entrevistas semiestruturadas com responsáveis acadêmicos, responsabiliza o Sinaes, por meio do Enade, por vir gradativamente corrompendo os pressupostos epistemológicos, axiológicos e pedagógicos que orientam a concepção dos currículos.

\section{Considerações finais}


A pesquisa realizada priorizou uma abordagem de caráter inventariante e descritiva, própria das pesquisas sobre o Estado da Arte (FERREIRA, 2002, p. 258), possibilitando aos pesquisadores um quadro diagnóstico sobre as teses e dissertações produzidas sobre o Enade, potencialmente útil como base de consulta para novos estudos a partir dos múltiplos recortes que podem ser realizados.

Constatou-se que o Enade é um tema que teve seu auge em termos de número de dissertações e teses, entre 2008 e 2009, podendo ainda gerar muitos outros estudos, visto que, com a posse da presidenta Rousseff, o Enade foi fortalecido, reestruturado, adquirindo novas funções no processo de avaliação e regulação da educação superior brasileira.

Concentrada na região sudeste do país, com 59,5\% das teses e dissertações defendidas sobre o Enade, a produção científica analisada permitiu identificar a concentração dos estudos nessa região do país, bem como a existência de dois formadores de mestres e doutores com maior número de teses orientadas sobre a temática estudada, ambos bolsistas produtividade: Claudette Maria Medeiros Vendramini, da UFS, e Wagner Bandeira Andriola, da UFC.

A pesquisa evidenciou ser o Enade uma temática de cunho multidisciplinar, com predominância de estudos no campo das ciências humanas, que apresenta um leque muito amplo de eixos temáticos, revelando as múltiplas interfaces existentes entre o Enade e os diversos âmbitos da educação superior.

A pesquisa permitiu constatar que, em sua maioria, os estudos realizados sobre o Enade se distanciam das discussões que dizem respeito aos componentes ideológicos existentes nas avaliações em larga escala, para focar aspectos mais técnico-operacionais, dentro de um leque que vai dos impactos e estratégias de aprimoramento no âmbito institucional às estratégias didáticopedagógicas no campo da aprendizagem e do desempenho dos estudantes, abrangendo inclusive aspectos técnicos sobre a forma de estruturação dos itens adotados nos instrumentos de avaliação externa.

No campo dos estudos sobre o Enade e a melhoria do desempenho institucional, fica explícita a preocupação com o estudo da realidade das IES federais (SOUZA, 2009; CAMPOS, 2009; EUSSEN, 2010; PEREIRA, 2010; RODRIGUES, 2008). No que se refere às contribuições do Enade para a melhoria de diversos cursos de graduação, fica evidente uma visão bastante positiva em 
torno desse instrumento de avaliação, na medida em que é visto como "deflagrador de alterações", de "mudanças significativas" e que presta "grandes contribuições" para as IES e seus cursos (ALVES, 2007; FONSECA, 2008; GRACIOSO, 2008; REIS, 2009; CAMPOS, 2009). Fatores de desempenho dos alunos no Enade, em diversos cursos de graduação, também se tornaram alvo de curiosidade científica (ANTUNES, 2008; SOUZA, 2008; MOREIRA, 2010; PERIM, 2007; SOUZA, 2007), incluindo preocupações teóricas numa perspectiva comparada entre o ENC e o Enade (BASTOS, 2007; SILVA, 2007; ARAGÃO, 2008; DEL RIO, 2008; SHEREMETIEFF, 2008), impactos do Enade nas matrizes curriculares dos cursos de graduação (SOUSA, 2009), estudos sobre questões específicas sobre as provas, tendo como base a Teoria da Resposta ao Item (OLIVEIRA, 2006; NOGUEIRA, 2008 e VEIGA, 2009) e os gêneros discursivos adotados nas questões do Enade 2006 (SILVA, 2009). Incluem-se também, estratégias didáticas para a melhoria do desempenho do aluno, como mapas conceituais (ALVARÃES, 2009), sistemas de tutores inteligentes (BORGES, 2009) e recursos da Tecnologia da Informação e Comunicação (GONÇALVES, 2009), além de preocupações com a formação de professores diante dos desafios impostos pelo Enade no campo da matemática, ciências contábeis e pedagogia (DE LARA, 2007; SANTANA, 2009; SOUZA, 2010).

\section{Referências bibliográficas}

ALVARÃES, Alberto Carlos Teixeira. O uso de mapas conceituais no curso superior de administração de empresas: um estímulo à aprendizagem significativa e à prática transdisciplinar. Petrópolis, 2009. Dissertação (Mestrado em Educação) - Universidade Católica de Petrópolis. Petrópolis, RJ, 2009.

ALVES, Luciene. O processo de avaliação do ensino superior e a atual configuração dos cursos de nutrição no triângulo mineiro e Brasil. Uberaba, 2007. Dissertação (Mestrado em Educação) - Centro Universitário do Triângulo. Uberaba, 2007.

ANTUNES, Marcelo Moreira. Aspectos interferentes na qualidade do curso de educação física do centro universitário da cidade sob a ótica do corpo discente. Rio de Janeiro, 2008. Dissertação (Mestrado em Educação Física) - Universidade Gama Filho. Rio de Janeiro, RJ, 2008.

ARAGÃO, José Euzébio de Oliveira Souza. Políticas de avaliação do ensino superior: o curso de administração em questão. São Carlos, 2008. Tese (Doutorado em Educação) - Universidade Federal de São Carlos. São Carlos, 2008. 
BASTOS, Alexandre Fleming Vasques. A reforma (neoliberal) da universidade no Brasil: um discurso (re)velador. Maceió, 2007. Dissertação (Mestrado em Educação) - Universidade Federal de Alagoas. Maceió, 2007.

BORGES, Fabrícia Neves. Uso de sistemas tutores inteligentes na compreensão de leitura. Dissertação Goiânia, 2009. (Mestrado em Engenharia Elétrica e de Computação) - Universidade Federal de Goiás. Goiânia, 2009.

BRASIL. Ministério da Educação. Comissão Especial de Avaliação da Educação Superior (CEA). Bases para uma nova proposta de avaliação da educação superior. Brasília: MEC/INEP/SESU, 2004.

BRASIL. Ministério da Educação. Sinaes - Sistema Nacional de Avaliação da Educação Superior: da concepção à regulamentação. Brasília: Instituto Nacional de Estudos e Pesquisas Educacionais Anísio Teixeira, 2007.

BRASIL. Ministério da Educação. Nota técnica do CPC. Brasília: Instituto Nacional de Estudos e Pesquisas Educacionais Anísio Teixeira, 2009.

BRITO, Márcia Regina de. O Sinaes e o Enade : da concepção à implementação. In. Avaliação, Campinas, v. 13, n. 3, p. 841-850, 2008.

CALDERÓN, Adolfo Ignacio; FERREIRA, António Gomes. Administração da educação no Brasil: um diálogo comparativo com as tendências temáticas da Revista Ibero-Americana de Educação. In. Revista Brasileira de Política e Administração da Educação, v.27, n.2, p. 321-339, maio/ago. 2011.

; POLTRONIERI, Heloisa; BORGES Regilson Maciel. Os rankings na educação superior brasileira: políticas de governo ou de Estado? In. Ensaio: Avaliação e Políticas Públicas em Educação, v. 19, n. 73, p. 813-826, out./dez. 2011.

CAMPOS, Aline Soares. Fatores institucionais associados à eficácia educacional dos cursos de graduação da Universidade Federal do Ceará (UFC): a opinião dos coordenadores. Fortaleza, 2009a. Dissertação (Mestrado em Educação) Universidade Federal do Ceará. Fortaleza, 2009a.

CAMPOS, Valter Gomes. Avaliação da Educação Superior: repercussões no projeto político-pedagógico do curso de pedagogia de UniEVANGELICA. Goiânia, 2009b. Dissertação (Mestrado em Educação) - Universidade Católica de Goiás. Goiânia, 2009b.

EUSSEN, Shirmenia Kaline da Silva Nunes. Sinaes: as diferentes faces da avaliação na UFRN. Natal, 2010. Dissertação (Mestrado em Educação) Universidade Federal do Rio Grande do Norte. Natal, 2010.

FERREIRA, Norma Sandra e Almeida. As pesquisas denominadas "Estado da Arte". In. Educação \& Sociedade, ano XXIII, no 79, p. 257-272, agosto 2002.

FONSECA, Denise Grosso da. Implicações do Exame Nacional de Desempenho dos Estudantes (Enade) nos processos avaliativos internos do curso de educação física do IPA. Porto Alegre, 2008. Tese (Doutorado em Educação) - Universidade do Vale do Rio dos Sinos. Porto Alegre, 2008.

GRACIOSO, Alexandre. Análise da eficácia escolar e do efeito-escola nos cursos de administração de empresas no Brasil. São Paulo, 2008. Tese (Doutorado em Administração de Empresas) - Fundação Getúlio Vargas/SP. São Paulo, 2008. 
GONÇALVES, Salete Pagaime. Uso de tecnologia no ensino e aprendizagem da trigonometria. São Paulo, 2009. Dissertação (Mestrado Profissionalizante em Ensino de Ciências e Matemática) - Universidade Cruzeiro do Sul. São Paulo, 2009.

LARA, Isabel Cristina Machado de. Exames Nacionais e as "verdades" sobre a produção do professor de matemática. Porto Alegre, 2007. Tese (Doutorado em Educação) - Universidade Federal do Rio Grande do Sul. Porto Alegre, 2007.

MOREIRA, Ana Maria de Albuquerque. Fatores institucionais e desempenho acadêmico no Enade: um estudo sobre os cursos de biologia, engenharia civil, história e pedagogia. Brasília, 2010. Tese (Doutorado em Educação) Universidade de Brasília. Brasília, 2010.

NOGUEIRA, Samantha de Oliveira. Enade: análise de itens de formação geral e de estatística pela TRI. São Paulo, 2008Dissertação (Mestrado em Psicologia) Universidade São Francisco. São Paulo, 2008.

OLIVEIRA, Karine Silva. Avaliação do Exame Nacional de Desempenho do Estudante pela Teoria de Resposta ao Item. São Paulo, 2006. Dissertação (Mestrado em Psicologia) - Universidade São Francisco. São Paulo, 2006.

PEREIRA, Cléber Augusto. Modelagem do Sistema de Avaliação de Conhecimento, segundo parâmetros do Enade, aplicável aos cursos superiores de graduação: uma proposta quanto a forma de avaliação nas IES. São Luís, 2010. Dissertação (Mestrado em Engenharia de Eletricidade) - Universidade Federal do Maranhão. São Luís, 2010.

PERIM, Gianna Lepre. Avaliação da educação superior: uma realidade na educação médica. Campinas, 2007. Tese (Doutorado em Educação) Universidade Estadual de Campinas. Campinas, 2007.

POLIDORI, Marlis Morosini. Políticas de avaliação da educação superior brasileira: Provão, Sinaes, IDD, CPC, IGC e ... outros índices. In. Avaliação, v. 14, n. 2, p. 439-452, 2009.

POLIZEL, Caio Eduardo de Guido. A representatividade do Enade e sua influência nos fatores críticos de sucesso relacionados à gestão do conhecimento em uma instituição superior privada. Vitória, 2009. Dissertação (Mestrado em Administração de Empresas) - Fundação Instituto Capixaba de Pesquisas em Contabilidade, Economia e Finanças. Vitória, 2009.

REIS, Carla de Borja. O uso dos resultados do Exame Nacional de Desempenho de Estudantes nos cursos de física da Universidade de Brasília e da Universidade Católica de Brasília. Brasília, 2009. Dissertação (Mestrado em Educação) Universidade de Brasília. Brasília, 2009.

$\mathrm{RIO}$, Claudio del. Os sistemas de avaliação da educação superior como ferramenta da gestão e competitividade. São Paulo, 2008.Dissertação (Mestrado em Educação) - Universidade São Marcos. São Paulo, 2008.

RODRIGUES, Viviane Aparecida. Enade - contribuições, avanços e limites do processo de avaliação na formação dos estudantes de graduação. Belo Horizonte, 2008. Dissertação (Mestrado em Educação) - Universidade Federal de Minas Gerais. Belo Horizonte, 2008. 
SANTANA, Ana Larissa Alencar. O perfil do professor de ciências contábeis e seu reflexo no Exame Nacional de Desempenho de Estudantes - um estudo nas universidades federais no Brasil. Ribeirão Preto, 2009. Dissertação (Mestrado em Controladoria e Contabilidade) - Universidade de São Paulo/Ribeirão Preto. Ribeirão Preto, 2009.

SHEREMETIEFF, Adriana Henrichs. Provão/Enade e Exame de Ordem com estratégias de avaliação externa dos estudantes e dos cursos jurídicos. Petrópolis, 2008. Dissertação (Mestrado em Educação) - Universidade Católica de Petrópolis. Petrópolis, 2008.

SILVA, Marcela Regina Vasconcelos da. Avaliação de rede no ensino superior: uma análise da abordagem de gêneros em questões discursivas do Enade. João Pessoa, 2009. Dissertação (Mestrado em Linguística) - Universidade Federal da Paraíba. João Pessoa, 2009.

SILVA, Francisco de Assis Batista da. Avaliação de proficiência no ensino médico e de enfermagem: Exame Nacional de Cursos (Provão) versus Exame Nacional de Desempenho de Estudantes (Enade). Brasília, 2007. Dissertação (Mestrado em Educação) - Universidade Católica de Brasília. Brasília, 2007.

SOUZA, Emerson Santana de. Enade 2006: determinantes do desempenho dos cursos de Ciências Contábeis. Brasília, 2006. Dissertação (Mestrado em Contabilidade) - Universidade de Brasília. Brasília, 2006.

SOUSA, Klinger Luiz de Oliveira. O caráter público do Sinaes e seu potencial de transformar o currículo das universidades. São Paulo, 2009. Tese (Doutorado em Educação) - Pontifícia Universidade Católica de São Paulo. São Paulo, 2009.

SOUZA, Maria Alice Veiga Ferreira de. Solução de problemas: relações entre habilidades matemáticas, representação mental, desempenho e raciocínio dedutivo. Campinas, 2007. Tese (Doutorado em Educação) - Universidade Estadual de Campinas. Campinas, 2007.

SOUZA, Laura Alves de. Análise das representações sociais da comunidade interna da Universidade Federal do Ceará - UFC - acerca da autoavaliação institucional. Fortaleza, 2009. Dissertação (Mestrado Profissionalizante em Políticas Públicas e Gestão da Educação Superior) - Universidade Federal do Ceará. Fortaleza, 2009.

SOUZA, Levi de Oliveira. Motivações para a escolha da licenciatura em matemática e pedagogia: um estudo com alunos da PUC/SP e UFMT. São Paulo, 2010. Dissertação (Mestrado Profissionalizante em Ensino de Matemática) Pontifícia Universidade Católica de São Paulo. São Paulo, 2010.

TEIXEIRA, Célia Regina. O "Estado da Arte": a concepção de avaliação educacional veiculada na produção acadêmica do Programa de Pós-Graduação em Educação: Currículo (1975-2000). In. Cadernos de Pós-Graduação educação, v.5, n.1, p. 59-66, 2006.

VEIGA, Julia Maria Barbosa. Evidências de validade para a prova do Enade de pedagogia. São Paulo, 2009. Dissertação (Mestrado em Psicologia) Universidade São Francisco. São Paulo, 2009. 